\section{Inclusion and Intellectual Disabilities: A Cross Cultural Review of Descriptions}

\author{
Deborah Tauba, $^{a}$, Megan Foster ${ }^{b}$
}

$\begin{array}{lr}\text { Received: } & 23 \text { September } 2019 \\ \text { Revised: } & 12 \text { November } 2019 \\ \text { Accepted: } \quad 21 \text { December } 2019 \\ \text { ISSN: 1307-9298 } \\ \text { Copyright (C) IEJEE } \\ \text { www.iejee.com }\end{array}$

DOI: $10.26822 /$ iejee.2020358221

\begin{abstract}
The benefits of inclusive practices for students with intellectual disabilities have been demonstrated in several countries; however, large-scale inclusive practices remain elusive. Having a clear understanding of how researchers define the terms inclusion and intellectual disability would support more cross-cultural collaboration and facilitate the generalization of practices. Addressed in this paper is the question of what themes, if any, exist in conceptualizing inclusion and intellectual disability across the peer-reviewed research of six countries, three of which have been identified as highly inclusive and three that have been identified as minimally inclusive. These findings may be used to further research into barriers and opportunities for inclusive practices for students with intellectual disabilities.
\end{abstract}

Keywords: Intellectual Disability, Inclusion, International, Education

\section{Introduction}

An argument has been made for the importance of inclusive practices in education and creating positive postsecondary outcomes for individuals and the larger community in terms of economic opportunities, quality of life, and safeguarding basic human rights (World Health Organization [WHO], 2011). The United Nations' Convention on the Rights of People With Disabilities (CRPD; United Nations, 2006) detailed the basic human rights all people should have and provided suggestions for policy and practice to achieve these goals by 2015 . The CRPD has been adopted by 161 countries with the express goal of reaffirming all people are entitled to human rights. Disability is recognized as a culturally constructed experience, so inclusion in daily community experiences with nondisabled peers is an integral part of building sustainable practices and policies. Yet, around the world, millions of children with disabilities remain who are segregated or not included at all in schools (Richler, 2017).

\section{Overview}

In this paper, we focus on students with intellectual disabilities (IDs) as defined by the American Association of Intellectual and Developmental Disability (AAIDD). The AAIDD (2019) define ID as "a disability characterized by significant limitations in both intellectual functioning and in adaptive behavior, which covers many everyday social and practical skills. This disability originates before the age of 18" (para. 1). Approximately $1-2 \%$ of the population have an ID (McKenzie, Milton, Smith, \& Ouellette-Kuntz, 2016). In the United States, compared to people without disabilities and those with other disabilities, people with IDs have worse economic, social, and quality of life outcomes (Bouck, 2012). They also have been consistently segregated in school (Kurth, Morningstar, \& Kozleski, 2014) despite research on inclusive practices indicating better in-school and postschool outcomes for students with IDs (White \& Weiner, 2004).

Because the CRPD is a legally binding international treaty with a supervisory body and implementation mechanisms, the definitions it uses have significant potential to create widespread and sustainable change. While each country, state, and even school will have a different context, if researchers clearly describe foundational definitions, such as what is meant by students with educational needs and inclusion, then an implementation framework would support scaling up at an international level. Until all people with disabilities, including those with IDs, are active and equal members of school communities, the goals of the CRPD remain unfulfilled. We use the construct of inclusion to mean all students, including those with IDs, are active members of the school and classroom community working toward the same goals as their peers without disabilities and have the possibility of those goals being achieved with appropriate accommodations and support.

\section{Constructing Disability}

The construction of disability has and continues to evolve (Buntinx \& Schalock, 2010). The medical model holds disability as a purely biological construct that impairs a person. While some progress has been made in psychological and medical professions in taking into account the lived experiences of disability, many countries' educational systems remain focused on solely a biological definition of disability (Sabatello, 2014). The result of such a medical model of disability is multifold, including viewing people with disabilities as passive recipients of aid, focusing on disability as something that should be cured-and if not cured then pitied, and aggregating disability experiences into an abstract "normal" experience that rarely mirrors lived experiences. Instead, what disability means depends in part on individual variables such as socioeconomic status, nationality, race, and gender. Conflating all experiences of a medical label into one aggregate experience may further marginalize individuals who have intersectional identities.

The social model of disability, on the other hand, attempts to take into account not only individual variables such as socioeconomic status and nationality but also the person with the disability as the central impetus of action and experience. The barriers that exist are not in the person but are a result of environmental and cultural inflexibility that conceptualizes a mythical normal and builds around that phantasmal original (Butler, 1999). The social model of dis- 
ability does not deny a biological aspect to disability; rather it acknowledges the experience of disability as going beyond the body to include social, financial, spiritual, educational, ecological, and other systems and experiences. While the CRPD allows for a wide range of disability constructions through its definition of disability as "those who have long-term physical, mental, intellectual or sensory impairments which in interac tion with various barriers may hinder their full and effective participation in society on an equal basis with others" (United Nations, 2006, para. 2), without an understanding of the social role of disability, the goals of the CRPD are unattainable. The AAIDD's (2019) definition of intellectual disability, which takes into account experiences and barriers outside of the individual, is better aligned to the goals of the CRPD than a strictly medical definition (Weller, 2011).

Using the social model of disability, it would be expected that definitions of disability vary by context and country. While this is true, the lack of common definitions of disability have been reported as challenges throughout the literature (Bolderson, Mabbett, Hvinden, \& van Oorschot, 2002). A comparative analysis for the European Commission outlined the problems with differing definitions of disability (Bolderson et al., 2002). The authors found each country in the European Union had varying definitions of disability, which often focused on aid and financial assistance received. The authors also argued the lack of commonality surrounding disability created problems for individuals who moved from one country to the next and also for doing any comparative work to inform policy (Bolderson et al., 2002)

\section{Inclusion}

Similar to disability, there is no one universally accepted definition of inclusion as it relates to education, though most researchers agree inclusion is more than merely sitting in the same classroom as one's peers (Nes, Demo, \& lanes, 2018) The act of inclusion involves acceptance, belonging, and an active and equitable role in the community. It is the belief all students have the right to an education equal to that of their peers. According to UNICEF (2013) in the State of the World's Children report, "Inclusive education entails providing meaningful learning opportunities to all students within the regular school system. It allows children with and without disabilities to attend the same age-appropriate classes at the local school, with additional, individually tailored supports as needed" ( $p$. 7). This definition aligns with other international organizations that promote inclusion, such as the United Nations, the Index of Inclusion, and Inclusion International.

The CRPD outlines the objective that people with disabilities have equal rights "to live in the community, with choices equal to others, and shall take effective and appropriate measures to facilitate full enjoyment by persons with disabilities of this right and their full inclusion and participation in the community" (United Nations, 2006, para. 1). Inclusion in educationa systems is a key driver for inclusion into the rest of the community. Studies have shown inclusion in general education classrooms with appropriate supports and services leads to better postsecondary outcomes than in segregated settings, so this may be a way to support an equitable opportunity for all people (Test et al., 2009). When schools segregate students based on academic ability or disability labels, they inadvertently set up a hierarchy of power later reflected in the larger society.

Research has shown when schools plan for all learners and make the content and environment accessible to all students, students with and without disabilities have improved academic outcomes. Conversely, when students with disabilities (SWDs) are in segregated settings, their opportunities to learn are hampered, and they have less positive postschool outcomes (Test et al., 2009). Additionally, in inclusive settings, students learn human variation is a natural expectation, a foundation that may support equity across the lifespan (UNICEF, 2013).

Researchers have shown inclusion improves academic performance in both literacy and mathematics for SWDs, including students with IDs (Peetsma, Vergeer, Roeleveld, \& Karsten, 2001; Ryndak, Morrison, \& Sommerstein, 1999). Students educated in inclusive classrooms spend more time on academic standards and have increased engagement on academics when compared to their peers in segregated settings (Wehmeyer, Lattin, Lapp-Rincker, \& Agran, 2003). In addition, research indicates students in inclusive settings have access to higher quality teaching practices and increased rigor and expectations (Hunt \& Farron-Davis, 1992). Furthermore, inclusion has been linked to increased attendance and overall health of SWDs (Dessemontet, Bless, \& Morin, 2012).

When SWDs are taught in the general education context with their peers, they are provided positive social and behavioral role models so they can learn social and behavioral skills that occur in a natural setting. This promotes both explicit and incidental learning, which has been shown to increase social skills and positive behavior (McDonnell, Mathot-Buckner, Thorson, \& Fister, 2001; McGregor \& Vogelsberg, 1998; Odom et al., 2004). When inclusion occurs in primary and secondary schools, it often results in inclusion after graduation.

Brown et al. (1986) found students who were educated in the general education context were also more likely than their peers in segregated settings to be employed after graduation. In fact, White and Weiner (2004) found inclusion was the number one predictor of employment postgraduation for students with IDs. Inclusion was a stronger predictor of employment than intelligence, behavior, or disability. Furthermore, it has been found that inclusion increases independence postgraduation (Blackorby, Hancock, \& Siegel, 1993; White \& Weiner, 2004). Increased employment and independence has been linked to increased quality of life for individuals with disabilities, including students with extensive support needs (Ryndak, Ward, Alper, Montegomery, \& Storch, 2010). In-school and postschool outcomes are improved when all students are provided the opportunity to learn alongside their peers. These outcomes support economic growth and stability, which will strengthen the larger society.

Because variations in the definition of inclusion exist, international comparisons of inclusive education may be an extremely arduous task. When researching inclusion, it was sometimes difficult to determine what inclusion referred to in that setting and research context. Furthermore, we focused on students with IDs, a population often excluded from formal education (Richler, 2017). Compounding the issue, many international articles do not define the student population, or they use the broad terms students with disabilities or students with educational needs, which makes it difficult, if not impossible, to determine if students with IDs are included in the study.

\section{Implementation Science}

While research has consistently shown positive outcomes for all students, creating, sustaining, and scaling up inclusive educational systems remains an elusive goal. To scale up inclusive practices, it would be helpful if researchers, advocates, and educators could pool their knowledge. However, there are differing understandings of disability labels and inclusion across the world (Taub, Foster, Orlando, \& Ryndak, 2017), making it difficult to use lessons learned in one context to inform instructional methods and systems change work in another setting. Implementation science is a methodology and framework for translating research into sustainable and systemic policies and practices (Learning Collaborative for Implementation Science in Global Brain Disorders, 2016) and a possible methodology for systematically promoting inclusive practices. The process 
includes understanding the specific drivers and context in which the intervention is being rolled out, consistently using data to evaluate and refine implementation, and using this process for continued refinement and scaling up.

Significant drivers of inclusive practices in CRPD are equity and economic growth. Some researchers and policymakers argue, when working toward change, "equity is not a by-product but an essential element-a value-of thoughtfully considered intervention design, learning agendas, and applied data collection and evaluation and research" (Farrow \& Morrison, 2019, p. 5). Inclusive education is an equity issue; indeed it may be the equity issue. Currently, UNESCO reports $90 \%$ of children with disabilities in the developing world do not attend school (Richler, 2017). Each country and state would have individualized drivers, levers, and barriers that necessitate consideration for implementation, improvement, and reproduction. These individualized aspects do not eliminate the possibility of international cooperative learning.

Educators, policymakers, families, and researchers need to learn from others' successes and barriers to facilitate effective educational systems. While each context has specific barriers to and levers for change, lessons may be learned across contexts. During research studies, clearly categorizing context and participants sets the stage for more unified learning. While a common definition of intellectual disability and inclusion may not be necessary across all countries, to learn from each other, a clear understanding of the terms and goals is required.

This research began with an initial question of whether there was a correlation between highly inclusive countries and those with a high quality of life for people with IDs. A literature search using the University of North Carolina, Greensboro University library online database was conducted to determine if there were international rankings of countries that included people with disabilities in schools, with a specific focus on identifying countries with high and low rates of school inclusion for students with IDs. Next, a Google search was conducted to identify other potential ranking sources. Another set of searches was conducted on quality of life indicators for people with IDs (economic standing, happiness, friendship). Quality of life and inclusion rankings from WHO, UNESCO, World Bank, and World Bank Group and Gallup Poll were reviewed and compared.

There was limited agreement across sources for where countries ranked in terms of inclusion levels and quality of life data for people with disabilities. Some common issues making the initial research question ineffective were aggregated data for all types of disabilities, differing definitions of common terms (such as intellectual disability and inclusion), and lack of detailed data on quality of life for people with IDs, all of which resulted in often conflicting pictures of a country's inclusion levels and/or quality of life for people with IDs. Ultimately, the World Report on Disability rankings of delivery of education in specific European countries (WHO, 2011) were used to identify and match countries with high and low inclusive educational practices because the data were clearest on location of service delivery (separate school/separate class/inclusive classes). As a result, we addressed a more percussive research question of what, if any, themes existed in conceptualizing inclusion and intellectual disability across the peer-reviewed research of six countries, three of which we identified as highly inclusive and three we identified as minimally inclusive.

\section{Methodology}

Six paired countries were identified based on population, geography (island vs. mainland), and inclusion levels, with one pair having relatively high levels of inclusion and the other having relatively low levels of inclusion. The list of countries was limited and thus near-population matches could not always be made. High levels of inclusion were determined based on Figure 7.3 in the World Report on Disability (WHO, 2011). Spain's population of 46 million had approximately $83 \%$ of SWDs in inclusive classes and the remaining $17 \%$ in segregated schools, and Spain was paired with Germany. Germany's 82.79 million population had almost the exact inverse inclusion rates with only $17 \%$ of SWDs included and $83 \%$ in segregated schools. Portugal and Belgium were paired due to similar population levels (10.31 million and 11.35 million, respectively). Portugal was identified as having $85 \%$ of SWDs in inclusive classes, $5 \%$ in segregated classes in typical schools, and $10 \%$ in segregated schools. In the chart, Belgium was divided into Flanders and Wallonia; however, for the purposes of this research, they were viewed as a single entity. The data from the World Report on Disability (WHO, 2011) were averaged as $91 \%$ of SWDs in separate schools and $9 \%$ in inclusive settings. The smaller population country with low inclusion rates was Latvia with 1.9 million people and approximately $18 \%$ inclusion placements, $12 \%$ of SWDs in segregated classes in typical schools, and the remaining $70 \%$ in segregated schools. There were two small population countries with high inclusion rates: Iceland and Norway. Iceland had 338,349 people, while Norway had 5.25 million. Finally, Norway was chosen over Iceland even though the population difference between the countries was larger due to additional variables in play with an island country. Norway had approximately $84 \%$ of SWDs in inclusive classrooms, $13 \%$ in segregated classes in a typical school, and $3 \%$ in segregated schools. Norway was paired with Latvia. Latvia had approximately $70 \%$ of SWDs in segregated schools, $10 \%$ in segregated classes in regular schools, and $20 \%$ in inclusive classes.

Next, we conducted another literature review using eight online library databases, such as JSTOR, WorldCat, and ProQuest Central. Several combinations of search terms were used, including the keywords intellectual disability, teaching, school, inclusion, special education needs, education, cognitive, and each identified country's name. The search was limited to peer-reviewed articles from 1980-2019. An initial review of titles was used to determine if the article had the potential to be included. Articles on nonrelated topics such as genetic testing or fish hatcheries were not included. We then reviewed the abstracts to determine which studies met the criteria of including students with IDs, being about or in inclusive primary or secondary school settings, and discussing or located in the country of interest. The remaining articles were acquired and read to ensure they matched eligibility criteria. Data were collected and entered into a database that included the country, definitions or characteristics of ID or students with special education needs (SENs), definitions or descriptions of inclusion or inclusive practices, number of students addressed, if appropriate, and additional notes on context or content.

We then used a modified hybrid approach to thematic analysis that incorporated both identifying themes important to answer the research questions while using the data to develop and uncover new themes during the analysis (Swain, 2018). We each reviewed a different set of articles and checked in several times throughout the process to compare terms used, data gathered, and to answer questions. All data were recorded in the database for future analysis.

\section{Results}

We initially identified 385 possible articles through the searches. The number of possible articles from each search was 151 from Norway, 100 from Germany, 81 from Spain, 30 from Belgium, 15 from Portugal, and one from Latvia. 
After reviewing the titles and abstracts, 66 potential papers remained: 19 from Norway, 18 from Germany, 13 from Belgium, 11 from Spain, four from Portugal, and one from Latvia. We rejected articles if the abstract did not target the identified country clearly or did not include discussion on students with IDs and inclusion. Articles that identified multiple countries were evaluated separately for each country to identify pertinent data.

Next, we read each remaining article to confirm it met the criteria and to collect data on constructs of students with IDs and components of inclusion or inclusive practices. During the second reading, seven articles were inaccessible, and additional articles were discarded due to the same reasons as in the abstract review. For instance, in five cases, one article in the bibliography mentioned the targeted country, but the article did not. Generalized papers on inclusion with no specific country mentioned that focused on philosophy or rights across the world were not included in these results, leaving 10 articles for analysis. The remaining 19 articles included eight from Norway, three from Germany, three from Portugal, two from Spain, two from Belgium, and one from Latvia.

\section{Defining Students with Intellectual Disabilities}

Understanding the definition of ID would vary across borders, the objective of this research was to look for common learner characteristics to identify themes related to this population. While the majority of papers defined students with SENs, 15\% expanded on this label to include a more precise description of what learner difficulties, SENs, IDs, or academic difficulties entailed. Articles from each of the countries referred to students with IDs yet never defined the criteria for ID. Two articles from Norway, on the other hand, had very clear definitions, including an article by Scharenberg, Rollett, and Bos (2019) who defined ID using operationalized boundaries from psychological assessments. Three articles from Germany had a bit more information about SENs than just that generic label. Henke et al. (2017) provided a less detailed definition but did include a bit of additional information by defining SENs with a focus on students who have a need in a learning domain. Weiss, Markowetz, and Kiel (2018) stated, "In Germany . . . 'moderate and severe ID' is a category of education; respectively, a certain area of special needs which is related to limitations in functioning (conceptual, social, practical)" (p. 838). Pijl, Frostad, and Flem (2008) argued both the medical and social models of disability are problematic when defining SENs for their study.

\section{Defining Inclusion}

Several authors provided definitions of inclusion that explained what it was by stating what it was not. For instance, authors stated inclusion was more than being in the room and had importance beyond social skills. Authors of two of the articles used Booth and Ainscow's (2002) Index for Inclusion: Developing Learning and Participation in Schools as a rubric for what inclusion should be. Other authors used the beyond access model of inclusion by Sonnenmeier, McSheehan, and Jorgensen (2005) as the bar for inclusion. These were the only studies that included physically sharing space, being social, and learning alongside peers without disabilities as a part of the criteria for defining inclusion. In the remaining articles, authors discussed inclusion without clarifying components of the definition or providing an overarching idea of inclusion as students being in the same classroom as peers without disabilities with a sole focus on the social realm.

The authors covered peer friendships, self-determination skills, teacher and student relationships, supports needed for student involvement, making academics accessible, teachers' perceptions of inclusion, the training teachers need to implement inclusive practices, and an overarching focus on building inclusion. There was overlap in topics between the high-inclusive and low-inclusive countries. Both included information on peer supports, making academics accessible, supports needed for students, and training needed to support teachers, as well as teachers' perceptions of inclusion and student and teacher relationships. There were two topics present only in the articles from low-inclusion countries: (a) an overall conversation on building inclusive classrooms or schools and (b) the skills teachers need to implement inclusion. The one topic present only in the high-inclusive countries was a study on student self-determination.

\section{Discussion}

In an effort to build a more complete understanding of educational inclusion with a goal of learning from how various countries have implemented large-scale systemic change, the original intent of this research was to create a protocol for comparing policies, laws, and practices of countries with high and low rates of inclusive education. The early findings indicated, while research consistently showed inclusive practices were beneficial, many studies did not include people with low incidence disabilities such as IDs, and, across each country, there were different definitions of both disability categories and inclusion. These basic differences in variables made it difficult to compare systems across borders. This initial investigation into differences in foundational definitions of intellectual disability and inclusion provides a starting point for researchers to develop clear protocols of explicit descriptions of these two constructs to contextualize local efforts and make it easier for researchers, educators, advocates, and policymakers to determine universal themes, if any, on including students with IDs as active participants in general education classrooms with their peers without disabilities as the norm rather than the outlier.

The most evident theme that emerged from the literature review was the lack of consistency found between articles and countries. In the literature, there were no common definitions of key terms, even in countries such as Germany that have a legal definition of the term intellectual disability. Without a description of the students served and a definition of inclusive education, a meaningful comparison between countries remains difficult and thus a barrier to improving and learning from other countries' practices. For example, many articles focused on the very broad term students with special education needs without explicitly defining the learner characteristics of those students included in the study, in some cases making it impossible to determine if students with IDs were included in the population of study. The definitions in the original 183 articles defined disability quite differently, with some articles including sex (female) and others including ethnicity in a larger construct of marginalization and disability.

The importance and value of recognizing disability as socially constructed does not preclude the need for researchers, educators, and policymakers to find patterns of what works to support various learner characteristics. For instance, in the United States, data are clear that students with IDs who are educated in segregated settings are less likely to be included and, upon graduation, are more likely to be unemployed, have few friends, and experience little independence (Brown et al., 1986; Butterworth et al., 2014). Without a common understanding of what learner characteristics comprise the construct of ID in the United States, it is only through disaggregating disability category data these patterns become clear; identifying the pattern allows researchers, educators, and policymakers to begin to deconstruct where barriers exist for these students. With common understandings across international studies, it would be possible to determine if there were practices or policies that support better postsecondary outcomes for these students that could be disseminated and implemented in other contexts. Having unclear understandings of learner characteristics makes it difficult to disseminate evidence-based practices across the world so each country does not have to start from scratch but instead can build from lessons learned. 
Similarly, the term inclusion can vary considerably, and, in the final articles used for analysis, only one of them provided clear characteristics for what inclusion should look like (Mortier, Van Hove, \& De Schauwer, 2010). Many of the articles included in the original dataset used "included" to mean all students are educated, regardless of setting. For instance, in the initial sample of papers, the focus was on including females, students from lower socioeconomic families, and students with physical disabilities. Other articles used the term "inclusion" or "included," but the study seemed to only occur in self-contained classes. Is inclusion merely sharing the same physical space? At a school level or a classroom level? Is inclusion primarily for social reasons? Or are academics just as important? We used a more comprehensive definition of inclusion that involves not only being in the same space but working with peers without disabilities on the same academic work, though it may be modified in terms of depth of knowledge and difficulty. The various definitions of inclusion may reflect larger societal beliefs about who is or is not worthy of an education, but the range of categories was a barrier to international comparisons.

Another theme that emerged when doing an initial search of datasets related to data and population. First, some countries lacked updated data on inclusion and disability, thus compounding the issue of consistency since it was unclear if progress had been made since the latest data were reported. Second, based on the report from the WHO (2011), larger countries were generally not as inclusive as smaller countries such as Iceland. This trend, along with the limited number of countries included in their dataset, made finding comparable countries challenging. For example, Spain has a relatively high rate of inclusion, and a population of 46 million was compared to Germany's low rate of inclusion and population of 82 million. Countries with larger populations face challenges smaller countries do not due to the number of students served and thus the increased number of SWDs served. As a result, we attempted to account for population by matching countries according to population; however, variations still exist.

Lastly, countries that relied on tracking systems had lower rates of inclusion. Germany, for example, places students into tracks at a young age based on perceived academic potential. Students are considered to be university bound or vocation bound and then educated accordingly. This system of tracking students invariably leads to segregation, where SWDs and those who struggle academically are placed into tracks that differ from their same-age peers. This system of tracking not only shapes a students' education but also their future life trajectory.

Why does it matter if researchers, educators, and policymakers review international literature on teaching students with IDs and inclusive practices? First, each day students are excluded from the general education classroom, they are losing opportunities to learn they cannot afford to lose. Second, as the CRPD, WHO, and UNESCO have argued, when a subgroup of the population is barred from education, their quality of life tends to be low, and their families have a loss of income due to caregiving requirements. Third, the tenets of implementation science have been identified as useful when trying to create sustainable, systematic change and improvement (Fixsen, Blase, Metz, \& Van Dyke, 2015), especially for change that requires attitudinal and behavioral shifts, as it takes into account local context. However, when the research and practice reported does not clearly detail the contexts in which they are working, including in this case the learner characteristics of the students and the characteristics of what is meant by inclusion, it is difficult to move from individual change to systemic development. Thus, not only were there very few articles on the practice or theory of including students with IDs, but those we found often provided little context from which others could learn when implementing change.

\section{Limitations}

A major limitation of this study was the lack of a more comprehensive ranking of inclusion than the World Report on Disability (WHO, 2011). This list focused solely on select European nations, leaving out many countries that should inform practice. It was used because it provided a clear and common construct for further inquiry that could later be extended to other countries. An additional concern was the low number of articles found overall, with only $5.5 \%$ of those articles meeting the inclusion criteria. This limited the understanding of inclusive education in the countries selected. It is possible the keywords were too detailed, which would have excluded articles of possible interest. In addition, we relied on university databases that resulted in very few articles written in languages other than English. Since the focus was on international education, it is likely there are many articles written in other languages that would have met the criteria. Another limitation was the lack of available datasets comparing educational placements in various countries. The dataset chosen only compared 30 European countries. This significantly limited the initial selection of countries and thus the articles we found.

\section{Future Recommendations}

Researchers who clearly detail the learner characteristics of the population in their studies and who provide detailed characteristics of what inclusion means in their context would support opportunities for cross-cultural learning. Describing disability categories or characteristics and clear explanations of educational placements would greatly reduce the confusion related to differing terminology. In addition, countries that do not currently collect and disaggregate data on their population of people with disabilities need to do so. The CRPD offers tools and guidance for data collection; however, there is no one way to collect this data as long as it includes, but is not necessarily limited to, the number of people and their age ranges who have various disabilities or learner characteristics (e.g., male/female, deaf, blind, ethnicity, requiring adapted intellectual and behavior supports across multiple settings), where they are getting their education at the classroom level (e.g., general education classroom v. separate classroom) and the amount of time there, as well as common contextual expectations or practices of what that schooling entails (e.g., active participation or sitting in the back of the room with an adult other than the teacher, academics or physical education, art or music, completing the same or similar work as their peers without disabilities or significantly different work). Postsecondary data are also necessary to examine quality of life levels for individuals with disability.

Ensuring children with disabilities receive a high-quality education in an inclusive environment should be a priority of all countries. To do this, and to fulfil the goals of the CRPD and ensure equity for people with disabilities, systemic barriers to inclusion need to be removed. The measurement of that progress requires clear data collection, monitoring, and analysis to regularly inform policies and practices.

\section{References}

American Association of Intellectual and Developmental Delays (AAIDD). (2019). Definition of intellectual disability. Retrieved from www.aaidd.org

Blackorby, J., Hancock, G., \& Siegel, S. (1993). Human capital and structural explanations of post-school success for youth with disabilities: A latent variable exploration of the National Longitudinal Transition Study. Paper presented to Special Education SIG at the annual meeting of the American Educational Research Association, Atlanta, GA. Retrieved from https://files.eric. ed.gov/fulltext/ED380914.pdf 
Booth, T, \& Ainscow, M. (2002). Index for inclusion: Developing learning and participation in schools. Retrieved from the Centre for Studies on Inclusive Education website: http://www.csie.org.uk/resources/inclusion-index-explained.shtml

Bolderson, H., Mabbett, D., Hvinden, B., \& van Oorschot, W. J. H. (2002). Definitions of disability in Europe: A comparative analysis [Final report]. London, England: Brunel University.

Bouck, E. C. (2012). Secondary students with moderate/ severe intellectual disability: Considerations of curriculum and post-school outcomes from the $\mathrm{Na}$ tional Longitudinal Transition Study-2. Journal of Intellectual Disability Research, 56, 1175-1186. doi:10.1111 /j.1365-2788.2011.01517

Brown, L., Rogan, P., Shiraga, B., Zanella Albright, K., Kesler, K., Bryson, F., Vandeventer, P., \& Loomis, R. (1986). A vocational follow-up evaluation of the 1984-1986 Madison Metropolitan School District graduates with severe intellectual disabilities. In L. Brown, R. Loomis, K. Zanella Albright, P. Rogan, J. York, B. Shiraga, A. Udvari Solner \& E. Long (Eds.), Educational programs for students with severe intellectual disabilities (Vol. XVI, pp. 1-19). Madison, WI: Madison Metropolitan School District.

Buntinx, W. H., \& Schalock, R. L. (2010). Models of disability, quality of life, and individualized supports: Implications for professional practice in intellectual disability. Journal of Policy and Practice in Intellectual Disabilities, 7 283-294. doi:10.1111/j.1741-1130.2010.00278

Butler, J. (1999). Gender trouble: Feminism and the subversion of identity. New York, NY: Routledge.

Butterworth, J., Smith, F. A., Hall, A. C., Migliore, A., Winsor, J., Domin, D., ... Hall, C. H. (2014). StateData: The nationa report on employment services and outcomes. Boston, MA: Institute for Community Inclusion.

Dessemontet, R. S., Bless, G., \& Morin, D. (2012). Effects of inclusion on the academic achievement and adaptive behaviour of children with intellectual disabilities. Journal of Intellectual Disability Research, 56, 579-587. doi:10.11 11/j.1365-2788.2011.01497

Farrow, F., \& Morrison, S. (2019). Placing equity concerns at the center of knowledge development. Retrieved from the Centern for the Study of Social Policy website: https:// cssp.org/resource/equity-at-the-center/

Fixsen, D., Blase, K., Metz, A., \& Van Dyke, M. (2015). Implementation science. International Encyclopedia of the Social and Behavioral Sciences, 11,695-702. doi:10.1016/ B978-0-08-097086-8.10548-3

Henke, T., Bogda, K., Lambrecht, J., Bosse, S., Koch, H., Maaz, K., \& Spörer, N. (2017). Will you be my friend? A multilevel network analysis of friendships of students with and without special educational needs backgrounds in inclusive classrooms. Zeitschrift Für Erziehungswissenschaft, 20, 449-474. doi:10.1007/s11618-017-0767

Hunt, P., \& Farron-Davis, F. (1992). A preliminary investigation of IEP quality and content associated with placement in general education versus special education classes. Journal of the Association for Persons With Severe Handicaps, 17, 247-253. doi:10.1177/154079699201700406

Kurth, J. A., Morningstar, M. E., \& Kozleski, E. B. (2014). The persistence of highly restrictive special education placements for students with low-incidence disabilities. Research and Practice for Persons With Severe Disabilities, 39, 227-239. doi:10.1177/1540796914555580
Learning Collaborative for Implementation Science in Global Brain Disorders. (2016). Toolkit: Overcoming barriers to implementation in global health. Retrieved from the Fogarty International Center, Center for Global Health Studies website: https://www.fic.nih.gov/About/ center-global-health-studies/neuroscience-implementation-toolkit/Pages/default.aspx

McDonnell, J., Mathot-Buckner, C., Thorson, N., \& Fister, S., (2001). Supporting the inclusion of students with moderate and severe disabilities in junior high school general education classes: The effects of classwide peer tutoring, multi-element curriculum, and accommodations. Education and Treatment of Children, 24, 141-160. Retrieved from www.jstor.org/stable/42899651

McGregor, G., \& Vogelsberg, R. T. (1998). Inclusive schooling practices: Pedagogical and research foundations. A synthesis of the literature that informs best practices about inclusive schooling. Pittsburgh, PA: Allegheny University of the Health Sciences.

McKenzie, K., Milton, M., Smith, G., \& Ouellette-Kuntz, H. (2016). Systematic review of the prevalence and incidence of intellectual disabilities: current trends and issues. Current Developmental Disorders Reports, 3, 104 115. doi:10.1007/s40474-016-0085-7

Mortier, K., Van Hove, G., \& De Schauwer, E. (2010). Supports for children with disabilities inregular education classrooms: an account of different perspectives in Flanders. International Journal of Inclusive Education, 14 543-561. doi:10.1080/13603110802504929

Nes, K., Demo, H., \& lanes, D. (2018). Inclusion at risk? Pushand pull-out phenomena in inclusive school systems: The Italian and Norwegian experiences. International Journal of Inclusive Education, 22, 111-129. doi:10.1080/ 13603116.2017.1362045

Odom, S. L., Vitztum, J., Wolery, R., Lieber, J., Sandall, S., Hanson, M. J., Beckman, P., Schwartz, P., \& Horn, E. (2004). Preschool inclusion in the United States: A review of research from an ecological systems perspective. Journal of Research in Special Educational Needs, 4, 17-49. doi:1 0.1111/J.1471-3802.2004.00016

Peetsma, T., Vergeer, M., Roeleveld, J., \& Karsten, S. (2001). Inclusion in education: Comparing pupils' development in special and regular education. Educational Review, 53, 125-135. doi:10.1080/00131910125044

Pijl, S. J., Frostad, P., \& Flem, A. (2008). The social position of pupils with special needs in regular schools. Scandinavian Journal of Educational Research, 52, 387-405. doi:10.1080/00313830802184558

Richler, D. (2017, November 30). Including children with disabilities in education: Inertia or tipping point? [Web log post]. Retrieved from the Global Partnership for Education website: https://www.globalpartnership.org/blog/including-children-disabilities-education-inertia-or-tipping-point

Ryndak, D. L., Morrison, A. P., \& Sommerstein, L. (1999). Literacy before and after inclusion in general education settings: A case study. Journal of the Association for Persons With Severe Handicaps, 24, 5-22. doi:10.2511/ rpsd.24.1.5

Ryndak, D. L., Ward, T., Alper, S., Montgomery, J. W., \& Storch, J. F. (2010). Long-term outcomes of services for two persons with significant disabilities with differing educational experiences: A qualitative consideration of the impact of educational experiences. Education and Training in Autism and Developmental Disabilities, 45, 323-338. 
Sabatello, M. (2014). A short history of the international disability rights movement. In M. Sabatello \& M. Schulze (Eds.), Human rights and disability advocacy (pp. 1324). Philadelphia: University of Pennsylvania Press.

Scharenberg, K., Rollett, W., \& Bos, W. (2019). Do differences in classroom composition provide unequal opportunities for academic learning and social participation of SEN students in inclusive classes in primary school? School Effectiveness and School Improvement, 30, 309-327. doi:10.1080/09243453.2019.1590423

Sonnenmeier, R. M., McSheehan, M., \& Jorgensen, C. M. (2005). A case study of team supports for a student with autism's communication and engagement within the general education curriculum: Preliminary report of the beyond access model. Augmentative and Alternative Communication, 21, 101-115. doi:10.1080/07434610500103608

Swain, J. (2018). A hybrid approach to thematic analysis in qualitative research: Using a practical example. Sage Research Methods Cases. doi:10.4135/9781526435477

Taub, D., Foster, M. H., Orlando, A.-M., \& Ryndak, D. L. (2017). Ethical considerations for inclusive practices for students with extensive support needs. In A. Gajewski (Ed.), Ethics, equity, and inclusive education (pp. 119144). doi:10.1108/S1479-363620170000009005

Test, D., Mazzotti, V. L., Mustian, A. L., Fowler, C. H., Kortering, L., \& Kohler, P. (2009). Evidence-based secondary transition predictors for improving postschool outcomes for students with disabilities. Career Development for Exceptional Individuals, 32, 160-181. doi:10.1177/0885728809346960

UNICEF. (2013). The State of the World's Children. Retrieved from https://www.unicef.org/sowc/

United Nations. (2006). The United Nations Convention on the Rights of People With Disabilities. Retrieved from https://www.un.org/development/desa/disabilities/ convention-on-the-rights-of-persons-with-disabilities.html

Wehmeyer, M. L., Lattin, D. L., Lapp-Rincker, G., \& Agran, M. (2003). Access to the general curriculum of middle school students with mental retardation: An observational study. Remedial and Special Education, 24, 262-272. doi:10.1177/07419325030240050201

Weiss, S., Markowetz, R., \& Kiel, E. (2018). How to teach students with moderate and severe intellectual disabilities in inclusive and special education settings: Teachers' perspectives on skills, knowledge and attitudes. European Educational Research Journal, 17, 837-856. doi:10.1177/1474904118780171

Weller, P. J. (2011). The Convention on the Rights of Persons With Disabilities and the social model of health: New perspectives (Monash University Faculty of Law Legal Studies Research Paper No. 20). Journal of Mental Health Law, 74-83. doi:10.2139/ssrn.2142323

White, J., \& Weiner, J. S. (2004). Influence of least restrictive environment and community based training on integrated employment outcomes for transitioning students with severe disabilities. Journal of Vocational Rehabilitation, 21, 149-156. Retrieved from https:// content.iospress.com/articles/journal-of-vocational-rehabilitation/jvr00263

World Health Organization (WHO). (2011). World report on disability. Retreived from https://www.who.int/disabilities/world_report/2011/en/ 